This is the accepted manuscript. To cite this publication, please refer to The Review of English

Studies, 72.303 (2021): 202-3.

\title{
Angela Esterhammer. Print and Performance in the 1820s: Improvisation,
}

Speculation, Identity. Pp. x +272 (Cambridge Studies in Romanticism). Cambridge: Cambridge University Press, 2020. Hardback, £75.

Conceived around the three multivalent concepts advertised by its subtitle, Angela Esterhammer's latest monograph is most fundamentally animated by a concept that she has devoted much of her career to elucidating. Underlying this book's wide-ranging reading of improvisation, speculation and identity as these three themes manifest in the literary culture of late-Romantic Britain is a close study of the early-nineteenth-century fascination for performance and performativity. For a corpus that might focus this wide brief, Esterhammer alights on a decade recently surging in Romanticist criticism following decades of neglect; the final decade of the period as it is conventionally constructed, which she argues is marked by a "distinctive episteme" (7) rendered tractable in an astonishing explosion of texts that scholars previously found to difficult to critique systematically. The book breaks new ground in offering a sequence of readings of periodicals, improvisations, parodic novels, and so on; parsing these as texts designed to question and complicate the standard separations between authorship and readership, bodies and books, words and realities: through such energetic experimentation with the dichotomies that condition textuality, late-Romantic writers investigate their cultural moment. Recognising these documents as privileged witnesses to their period that require a particular mode of reading, Esterhammer offers a theory of cultural production predicated on performativity, moulding the latter concept with an eye to recent advances in media studies and demonstrating the media concept that organised the 1820 s was deeply performative. The central term in the late-Romantic life of letters is not medium, then, but performance, which here designates a complex of positional acts through which authors and readers reciprocally and dynamically encode as interpersonal their roles in the informational system, albeit in a highly conscious fashion that tends to literature performance as theatricality. In short, Esterhammer asks that we shift our understanding of 
Romantic media ecology; from the notion of distance technologically overcome that determines postRomantic ideas of mediality towards notions of participation, roleplay, and collective experience. In this sense, she argues, in a line that cries out for further development in future work, "the 'performance concept' of the late-Romantic era seems to resonate with some of the ways in which media theory is now evolving." (10-11)

The book's strongest and most invigorating chapter is its first, which sets up the framework rehashed above. Deftly interlacing recent trends in Romanticist scholarship and literary studies, it will prove inspiring to critics operating across the nineteenth century and beyond. Esterhammer demonstrates the urgency to reverse a current tendency to discount the final decade of the Romantic period as enervated and effete in its productions by offering a set of concepts and ideas attended to the complexities of a subperiod that knows itself to be transitioning between two greater and more confident eras of cultural production. Having thus bucked the "institutional structures organised along Romantic and Victorian lines" (5), the book offers a six-chapter rogues' gallery of representative texts and persons which unlock Romanticism's lost decade by demonstrating the questions and confusions that underlie its enthusiasm for highly self-reflective and seemingly peripheral genres. The chapters on the noted improvisers Charles Matthews and Tommaso Sgricci stand out; both of them personalities who embody and live out their texts: previously studied by Esterhammer, they are here more powerfully situated and analysed, opening up promising avenues for future research on lived textuality. Also impressive are those sections that take up lesser-read writers and texts-Galt's Sir Andrew Wylie, Alexis's Walladmor, the periodical The Bachelor's Wife, and so on-and play these off against more canonical work to demonstrate the critical benefits of taking a wide view of late-Romantic writing. The reading of familiar touchstones in print-cultural analysis like the "pseudo-persons" of Blackwood's (38) and the doubles of Hogg's Private Memoirs and Confessions is greatly enriched by this contextualisation: no longer the exclusive province of the Great Unknown or similarly famous experimenters, texts and practices that muddle the structures of identity and truth that organise smooth transfers of information grow resonant with each other, pointing readers forward to wider cultural trends that had previously remained largely obscured. Given the panoply of texts and authors examined, it is remarkable that the book never loses track of its overarching themes, and adroitly cross-references texts to weave a coherent narrative. 
Lucidly written and meticulously researched, Esterhammer's monograph at once takes in a long tradition of Romanticist scholarship and prepares the field for future development. While the study closely affiliates with the historicist tradition, advocating a mode of reading that develops James Chandler's enduringly important work, and integrates significant inspiration from book history, its engagement with media theory is perhaps its most significant contribution to Romanticist and literary criticism. In modelling how research at the intersection of literary criticism and media studies may complicate accepted historiographies of literature and historicise concepts of mediality, this book is at is most suggestive, even if an outline of such future work is left implied. In her final paragraphs, Esterhammer notes that " $[t]$ he features that once led literary historians to skim over the late-Georgian period are the very features that now make it look trendsetting" (209): this, in the final analysis, is the book's most exciting accomplishment; to gesture at a perspective that renders Romanticism, and late Romanticism in particular, a key moment as we begin to understand our present. 